\title{
Supraclavicular Brachial Plexus Block: Effect of Using Dexmedetomidine as Adjuvant to Ropivacaine. A Randomized Double Blind Study
}

\author{
Priyanka Bansal ${ }^{1}$, ML Khatri, ${ }^{2}$ KL Garg, ${ }^{3}$ \\ ${ }^{1}$ Assistant Professor, ${ }^{2}$ Associate Professor, ${ }^{3}$ Professor and Head, \\ Deptt. of Anaesthesiology and Critical Care SGT University, Chandu Budhera, Gurgaon, Haryana.
}

\begin{abstract}
Background And Aims: Brachial plexus block is the cornerstone of regional anaesthesia practice. Various adjuncts have been used as adjuvants to ropivacaine in the past. This study was done to see the effect on duration of analgesia using dexmedetomidine as adjuvant to ropivacaine 0.5\% in supraclavicular brachial plexus block (SBPB).

Method: A total of eighty patients undergoing elective upper limb surgeries under SBPB were enrolled for study. The patients were divided into two groups of 40 patients each and given $29 \mathrm{ml}$ ropivacaine $0.5 \%$ alone $(g p R)$ or $29 \mathrm{ml}$ ropivacaine 0.5\% along with dexmedetomidine $100 \mu \mathrm{g}(\mathrm{gp} \mathrm{D})$. Sensory block was assessed by Hollmen scale and motor block by Bromage scale. Onset time of sensory and motor block, total duration of sensory and motor block, duration of analgesia and total analgesic consumption were recorded as primary end point. Patients were monitored for level of sedation, VAS scores and any side effects, intraoperatively and post operatively.
\end{abstract}

Results: Inspite of similar demographic profile, sensory and motor block onset times were shorter in dexmedetomidine group $(\mathrm{gp} D)$ than ropivacaine only group $(\mathrm{gp} R)$.Total duration of sensory and motor block were significantly longer in $g p D$ as compared to gp $R$. Total duration of analgesia was longer in $g p D$ where total analgesic consumption was also much less than gp $R$.

Conclusion: Addition of $100 \mu \mathrm{g}$ of dexmedetomidine to $0.5 \%$ ropivacaine in SBPB for arm and forearm surgeries shortens the onset of motor and sensory block, prolongs the total duration of block and total duration of a pain free period without significant side effects.

Keywords: supraclavicular block, dexmedetomidine, ropivacaine

\section{Introduction}

"For all the happiness mankind can gain is not in pleasure but in rest from pain"- John Dryden. ${ }^{1}$ The International Association for the Study of Pain defines pain as an "unpleasant sensory and emotional experience associated with actual damage or potential tissue damage or described in terms of such damage". ${ }^{2}$ From time immemorial, attempts were made to relieve the pain of surgical intervention by various means. The role of peripheral nerve block (PNB) has expanded from the operating suite into the arena of postoperative and chronic pain management.

The supraclavicular technique was used by Kulenkampff in 1912 revealed that the nerves supplying the arm and the forearm are geographically grouped closely together in the brachial plexus and a single injection could provide analgesia for the whole limb. ${ }^{3}$ This technique avoids all complications of general anaesthesia like interference with general body physiology, stress response to intubation, loss of protective reflexes and operation theatre pollution. Numerous routes to perform brachial plexus block have been described, like Supraclavicular, Interscalene, Infraclavicular and Axillary. The supraclavicular route was used in this study as it is easy to perform, small volume of local anaesthetic solution is required as three trunks are compactly arranged resulting in a rapid onset of reliable blockade. Lanz et al(1983) showed that blockade of the brachial plexus with a supraclavicular technique directed near the first rib provides the most reliable, uniform, and predictable anaesthesia for the upper extremity. ${ }^{4}$ Since the introduction of first brachial plexus block using cocaine by Halstead (1884) the technique of brachial plexus block has evolved from classical blind technique to use of nerve stimulators and ultrasound guidance for supraclavicular brachial plexus block. ${ }^{5}$

Ropivacaine is a long-acting amide local anaesthetic with a potentially improved safety profile when compared to bupivacaine. ${ }^{6,7}$ Ropivacaine is less lipophilic than bupivacaine and is less likely to penetrate large myelinated motor fibres, resulting in a relatively reduced motor blockade. Ropivacaine has a greater degree of motor sensory differentiation. It has selective action on the pain-transmitting $\alpha, \beta$ and $\mathrm{C}$ nerves rather than $\mathrm{A} \beta$ fibres, which are involved in motor function. Various studies have investigated several adjuncts, including opioids $^{8}$, clonidine ${ }^{9}$, neostigmine ${ }^{10}$, hyaluronidase ${ }^{11}$ and dexamethasone ${ }^{12,13,14}$ Dexmedetomidine, the newer drug, is a potent $\alpha 2$ adrenoceptor agonist, and about eight-times more selective towards the $\alpha 2$ adrenoceptor 
than clonidine. ${ }^{15,16}$ In previous clinical studies, administration of intravenous dexmedetomidine has shown to produce significant opioid sparing effects as well as a decrease in inhalational anaesthetic requirements. ${ }^{17}$ In humans, it has been used in various strengths as an adjunct to local anasthetics to prolong post-operative analgesia in various peripheral blocks ${ }^{18,19}$. A study done by Anjan das et al using dexmedetomidine $100 \mu \mathrm{g}$ and ropivacaine $0.5 \%$ concluded a significant prolongation of time of block and duration of analgesia. ${ }^{20}$ This study formed the basis of our study and the current study was designed to further confirm the hypothesis that dexmedetomidine when added as an adjuvant to $0.5 \%$ ropivacaine in supraclavicular brachial plexus block using a nerve stimulator enhanced the onset and duration of sensory and motor block and duration of analgesia without causing any major hemodynamic instability or any other systemic side effects.

\section{Materials And Methods}

The present study was conducted in the Operation theatres of Department of Anaesthesiology and Critical Care over a period of 1 year from july 2015 to june 2016.

Selection of Patient: A total of 80 patients undergoing elective upper limb surgeries were included in the study after taking permission from the institutional ethics Committee. The purpose and entire anaesthetic procedure was explained in detail to them and written informed consent was taken from all the patients. Inclusion Criteria: Age 18 -60 years of either sexes, Body weight of $50 \mathrm{~kg}$ and above, ASA physical status I and II and patients listed for upper limb surgeries involving arm and forearm.

Exclusion Criteria: Patients who were unwilling for the procedure, in ASA physical status III and above, having neurological lesions in the upper limb to be operated upon, with diabetic neuropathy, psychiatric patients, patients with history of allergy to local anaesthetics, with infection / swelling at proposed site of injection, or patient on alpha blockers or beta blockers or with bleeding disorders or patients on anticoagulants, or with any contraindication for peripheral nerve block were excluded from the study. All patients underwent routine pre-anaesthetic evaluation. After taking detailed history and clinical examination, routine and specialised investigations as per patient and case requirement were done. The patients were randomly divided into two groups of 40 each. Block was administered using the following combination of drugs

Group 1: Ropivacaine $0.5 \%(29 \mathrm{ml})+$ Normal saline $(.9 \%) 1 \mathrm{ml}$ to make a total volume of $30 \mathrm{ml}$.

Group 2: Ropivacaine $0.5 \%$ (29 ml) + Dexmedetomidine $100 \mu \mathrm{g}$ to make a total volume $30 \mathrm{ml}$.

All the patients were given Tablet Alprazolam $0.25 \mathrm{mg}$ and tab ranitidine $150 \mathrm{mg}$ orally the night before surgery. All selected cases were advised to remain nil orally for fluids and solids as well, at least six hours prior to the time of performing the block. All patients were explained the Visual analogue scale (VAS) on 0-10 where 0 denoted no pain and 10 denoted worst pain.

In the operating room, an IV cannula was inserted in the contralateral upper limb and standard ASA monitoring was applied. Heart rate (HR), systolic arterial pressure (SAP) and diastolic arterial pressure (DAP), oxygen saturation (SpO2) and sedation score according to Ramsay sedation scale (RSS) were recorded before the block was performed. ${ }^{21}$

\section{Ramsay sedation score}

1 Anxious, agitated, restless

2 Cooperative, oriented and tranquil

3 Responding to commands only

4 Brisk response to light glabellar tap

5 Sluggish response to light glabellar tap

6 No response to light glabellar tap

Under strict aseptic precautions and after infiltration of $2 \mathrm{ml}$ of lidocaine (2\%) locally. All blocks were performed by the same anaesthesiologist, who was different from the one who prepared the study drugs. So this study was completely unbiased. Standard monitoring (non-invasive blood pressure, pulse oximetry and ECG) was commenced upon arrival to the preoperative holding area.

A 22-gauge 50-mm insulated stimulation short bevel needle (Stimuplex ${ }^{\circledR}$ A, B/Braun Medical, Germany) connected to a nerve stimulator (Stimuplex®-DIG, B/Braun, Germany) was used for all blocks. The initial nerve stimulator settings were $1.5 \mathrm{~mA}$ with an impulse duration of $0.1 \mathrm{~ms}$. The needle position was considered to be adequate when the motor response in the hand or wrist was obtained and remained visible with a maximum current of $0.5 \mathrm{~mA}$.

Sensory block in the territories of median, ulnar, radial and musculocutaneous nerves was assessed by pinprick test using Hollmen scale ${ }^{22}$ and findings were recorded at an interval of every 2 min from time- 0 till complete sensory block was achieved i.e Hollmen Score $=4$ 


\section{Hollmen scale:}

Score 1 = Normal sensation of pinprick.

Score 2 = Pin prick felt as sharp pointed but weaker compared with same area in the other upper limb.

Score $3=$ Pin prick recognized as touch with blunt object.

Score 4 = No perception of pin prick.

Motor block was evaluated by thumb abduction (radial nerve), thumb adduction (ulnar nerve), thumb opposition (median nerve) and flexion at the elbow (musculocutaneous nerve) using Bromage scale for upper extremity: ${ }^{23}$

0: Able to raise the extended arm to $90^{\circ}$ for full 2

seconds.

1: Able to flex the elbow and move the fingers but

unable to raise the extended arm.

2: Unable to flex the elbow but able to move the

fingers.

3: Unable to move the arm, elbow and fingers

The onset time of the sensory and motor blocks were recorded by assessment of the block every 3 min for 30 min after injection of the drug. The HR, SAP, and DAP were documented at every 5 min for 30 min and then every 10 min till completion of surgery. Sedation was assessed by RSS every 5 min for 30 min and then every 10 min till completion of surgery.

A successful block was defined as a grade 4 on Hollmen scale (sensory block in 3 or more nerve territories). The time of onset of sensory block was defined as the time between the administration of the drug and complete sensory block. Duration of sensory block was defined as the time taken from the administration of drug to complete recovery of anaesthesia on all nerves. The duration of analgesia was defined as the time to attain a visual analogue score (VAS) of $>4$ after the drug administration.

A grade 3 motor block on bromage scale was defined as complete motor block. Onset time of motor block was defined as the time interval between the completion of the drug administration and complete motor block. Duration of motor block was defined as the time to the recovery of complete motor function of the hand and forearm after the administration of drug.

The block was considered incomplete when any of the segments supplied by median, radial, ulnar and musculocutaneous nerve did not have analgesia even after $30 \mathrm{~min}$ of drug injection. These patients were supplemented with intravenous fentanyl $(1 \mu \mathrm{g} / \mathrm{kg})$ and midazolam $(0.02 \mathrm{mg} / \mathrm{kg})$. When more than one nerve remained unaffected, it was considered a failed block. In this case, general anaesthesia was given intraoperatively.

The ECG was monitored constantly and only the significant changes (if any) from the base line was recorded under the heading of intraoperative complications. Duration of surgery, torniquet time and type of surgical procedure done were recorded.

Following intra-operative and post operative complications were looked for - inadequacy of block, any reaction at injection site like haematoma, persistent bradycardia, persistent hypotension, oversedation- sedation score $>4$, any respiratory distress, fall in respiratory rate to $<10$ per min, fall in $\mathrm{SpO} 2$ to $<90 \%$, pruritus, any symptoms or signs of local anaesthetic toxicity, any significant ECG changes and Horner's syndrome. Intra-operative medication given (if any) for sedation or management of complications were also noted and recorded. At the end of the procedure, quality of operative conditions were assessed according to the following numeric scale: ${ }^{24}$

Grade 4: (Excellent) No complaint from patient

Grade 3: (Good) Minor complaint with no need for the supplemental analgesics

Grade 2: (Moderate) Complaint that required supplemental analgesia

Grade 1: (Unsuccessful) Patient given general anaesthesia

Assessment of blood loss was done and fluid was administered as per the loss. The intra- and postoperative assessment was done by an anaesthesiologist who was unaware of the drug used. Post-operative Monitoring: After the completion of the surgery patient was shifted to post operative recovery ward without prescribing any analgesics in any form. Patient was monitored till the complete recession of sensory as well as motor block occurred and till the time patient did not demand any analgesic or VAS Score was recorded as $\geq 3$. On reaching that point of time, patient was given systemic analgesic Inj Diclofenec Sodium $75 \mathrm{mg}$ IM or Inj Tramadol $100 \mathrm{mg} \mathrm{I} / \mathrm{V}$ as per individual requirement. Total analgesic consumption in 24 hours was recorded in both the groups.

Parameters recorded in the post operative period for 24 hours were as follows:- PR, SBP, DBP, MAP and RR were recorded at an interval of every 30 minutes. Sensory block was evaluated and recorded by 
Hollmen scale at an interval of every 30 minutes till the time when it fell to 1 or patient complained of pain in the post operative period. Pain was assessed by Visual Analogue Scale (VAS). VAS was recorded and assesed at an interval of every 30 minutes till the score $\geq 3$. Motor Block was evaluated and recorded at an interval of every 30 minutes till the time when BS score was $<3$ in the postoperative period. Time of first dose of postoperative systemic analgesic was on the basis of VAS score $\geq 3$ or on demand made by the patient (whichever was early) and was noted for use as analgesia time.

Post operatively CXR was done after six hours from block administration or early if patient showed any clinical evidence of pneumothorax and finding was recorded, with their respective management. Postoperative follow up was done after 2 weeks for any neurological deficit or any other delayed complication.

\section{Statistical Analysis}

The data was analysed by SPSS version (Statistical Package for Social Sciences) software. Power analysis was not performed before the study. Interim analysis was performed with a power analysis and calculated from the values taken from the $40 \mathrm{U}$ of group R and group D after the study was initiated. Statistical power was calculated to be $99.9 \%$ for duration of analgesia period as $\alpha-0.05, \beta-0.001$, and was calculated to be $99.9 \%$ for sensory block period as $\alpha-0.05, \beta-0.001$.

Unpaired t-test was applied for demographic data, haemodynamic parameters, onset and duration of sensory and motor blockade and duration of analgesia. For duration of analgesia and total duration of sensory and motor block unpaired t-test was reconfirmed with wilcoxon W and Mann- Whitney U tests. Fisher exact test was applied for assessment of quality of block. $P$-value was considered significant if $<0.05$ and highly significant if $<0.001$.

\section{Results}

All the patients completed the study and there was no drop out or any case of block failure. There was no statistically significant difference among the patients in the two groups with respect to age, height, weight, BMI, sex ratio, duration of surgery, type of surgery and the ASA physical status [Table 1]. The sensory and motor block onset was significantly quicker in group $\mathrm{D}$ than in group $\mathrm{R}$. The mean sensory block onset time was $12.68 \pm 2.24 \mathrm{~min}$ in group $\mathrm{D}$ as compared to $21.1 \pm 6.84 \mathrm{~min}$ in group $\mathrm{R}$. The mean motor block onset time was $17.41 \pm 5.61 \mathrm{~min}$ in group D when compared to $32.64 \pm 6.44 \mathrm{~min}$ in gp R. [Table 3]. The duration of sensory as well as motor block was significantly prolonged in group $\mathrm{D}$ as compared to group $\mathrm{R}$. The duration of sensory block was more in group $\mathrm{D}(802.33 \pm 154.66 \mathrm{~min})$ as compared to $492.54 \pm 78.14 \mathrm{~min}$ in group $\mathrm{R}$ and the difference was highly significant.

The pain free period (time to request of first dose of analgesia) was significantly prolonged in group D (approx. 16 hours) as compared to approx. 10 hours in group R.

The total analgesic consumption in 24 h postoperatively was significantly higher in group R than group D.

Table 1: Demographic profile

\begin{tabular}{|l|l|l|l|}
\hline variable & gp R & gp D & p value \\
\hline Age $(\mathrm{yrs})$ & $38.50 \pm 15.54$ & $42.14 \pm 9.66$ & .65 \\
\hline Height $(\mathrm{cm})$ & $159.42 \pm 6.85$ & $161.54 \pm 4.43$ & .90 \\
\hline Weight $(\mathrm{kg})$ & $72.44 \pm 14.54$ & $69.31 \pm 10.81$ & .53 \\
\hline BMI $\left(\mathrm{kg} / \mathrm{m}^{2}\right)$ & $25.12 \pm 3.14$ & $26.81 \pm 2.66$ & .24 \\
\hline Duration of surgery (min) & $100.64 \pm 40.51$ & $98.12 \pm 39.68$ & .65 \\
\hline Tourniquet time (min) & $110.12 \pm 15.32$ & $102.54 \pm 10.33$ & .74 \\
\hline $\begin{array}{l}\text { Gender } \\
\begin{array}{l}\text { Male } \\
\text { female }\end{array}\end{array}$ & $16: 14$ & $20: 10$ & .63 \\
\hline ASA grade (I:II) & $21: 9$ & $19: 11$ & .88 \\
\hline
\end{tabular}

(Value in no of cases) 


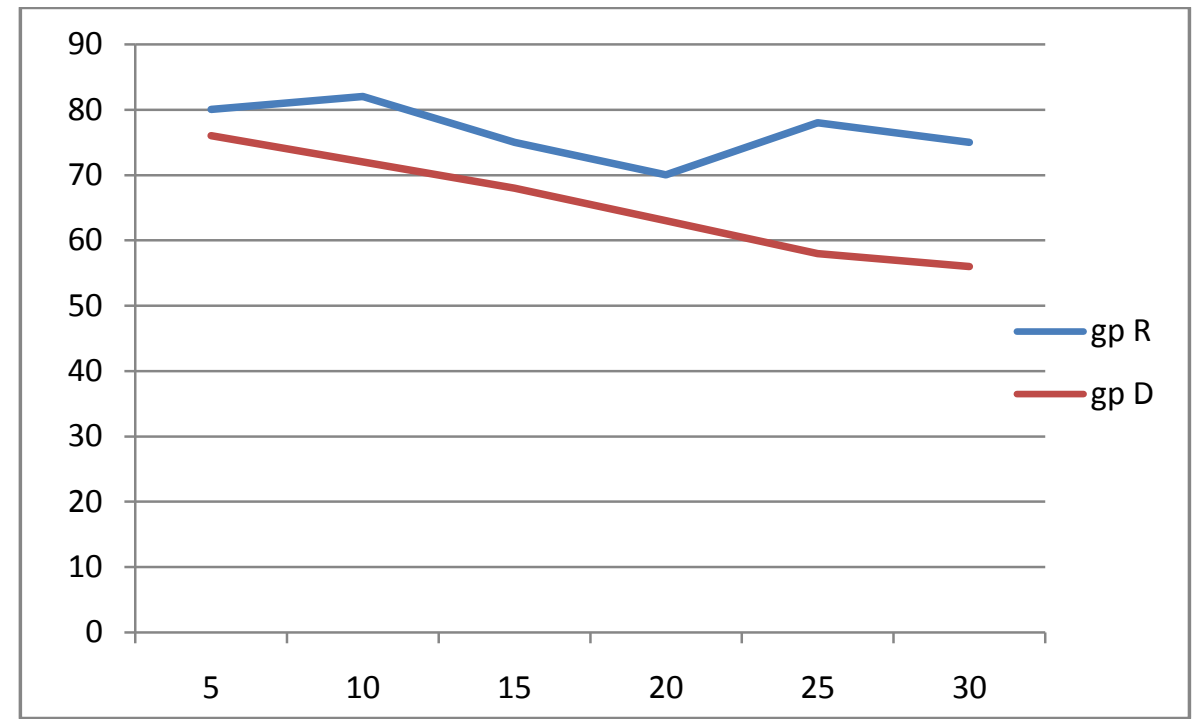

Mean Heart Rate In First Hour

Table 2: Types of surgeries/ Indication

\begin{tabular}{|l|l|l|l|l|}
\hline & Surgery & gp R & gp D & p value \\
\hline 1 & Fracture both bone forearm & 9 & 8 & .74 \\
\hline 2 & $\begin{array}{l}\text { IM locked nailing for diaphyseal forearm } \\
\text { fractures }\end{array}$ & 5 & 6 & .33 \\
\hline 3 & Percutaneous K wire fixationin colle's fracture & 5 & 4 & .25 \\
\hline 4 & Radial head fractures/ulna fractures & 6 & 7 & .84 \\
\hline 5 & Fracture distal humerus & 2 & 3 & .47 \\
\hline 6 & Monteggia/Galaezzi fracture dislocation & 3 & 2 & .53 \\
\hline
\end{tabular}

(Value in number of cases) (IM intramuscular)

Table 3: Characteristic of sensory and motor block, duration of analgesia after supraclavicular block(SBPB)

\begin{tabular}{|l|l|l|l|l|}
\hline & Block characteristic & gp R & gp D & p value \\
\hline 1 & Onset time of sensory block & $21.11 \pm 6.84$ & $12.68 \pm 2.24$ & $<0.001$ \\
\hline 2 & Onset time of motor block & $32.64 \pm 6.44$ & $17.41 \pm 5.61$ & $<0.001$ \\
\hline 3 & Duration of sensory block & $492.54 \pm 78.14$ & $802.33 \pm 154.66$ & $<0.001$ \\
\hline 4 & Duration of motor block & $478.12 \pm 122.68$ & $710.12 \pm 138.76$ & $<0.001$ \\
\hline 5 & Duration of analgesia & $584.76 \pm 158.04$ & $968.0 \pm 138.54$ & $<0.001$ \\
\hline
\end{tabular}

(Time in minutes)

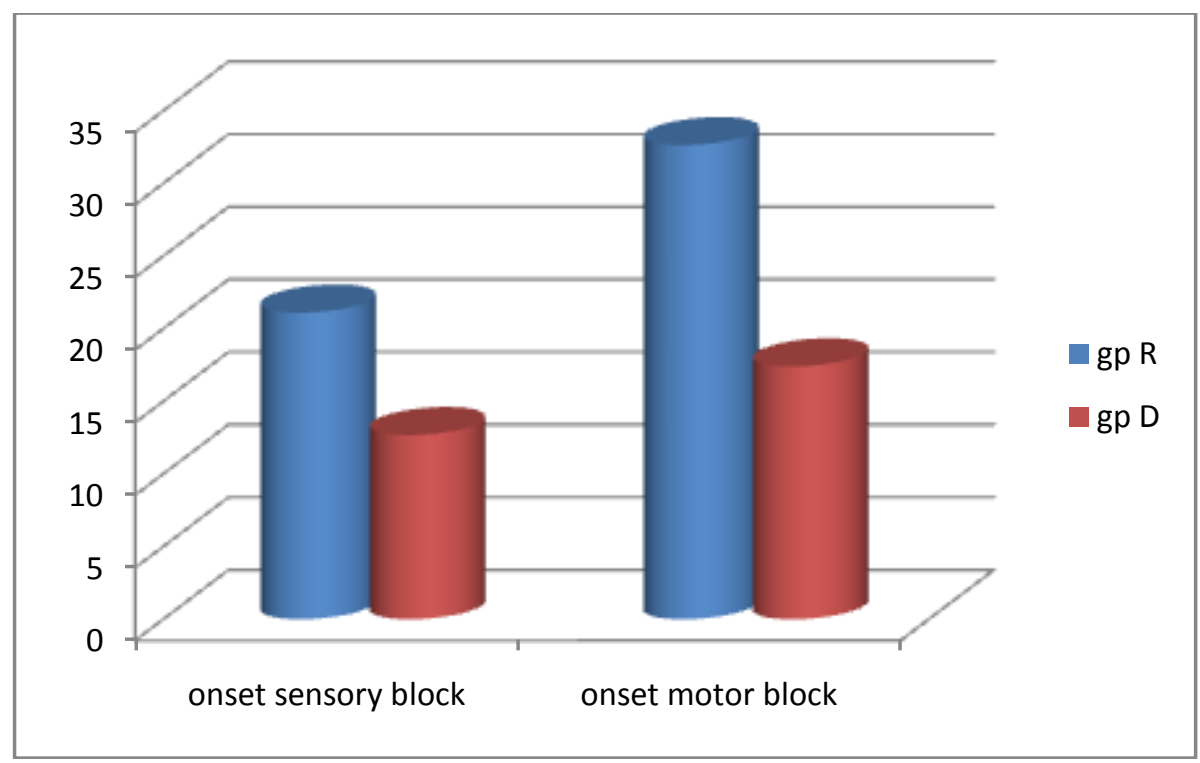




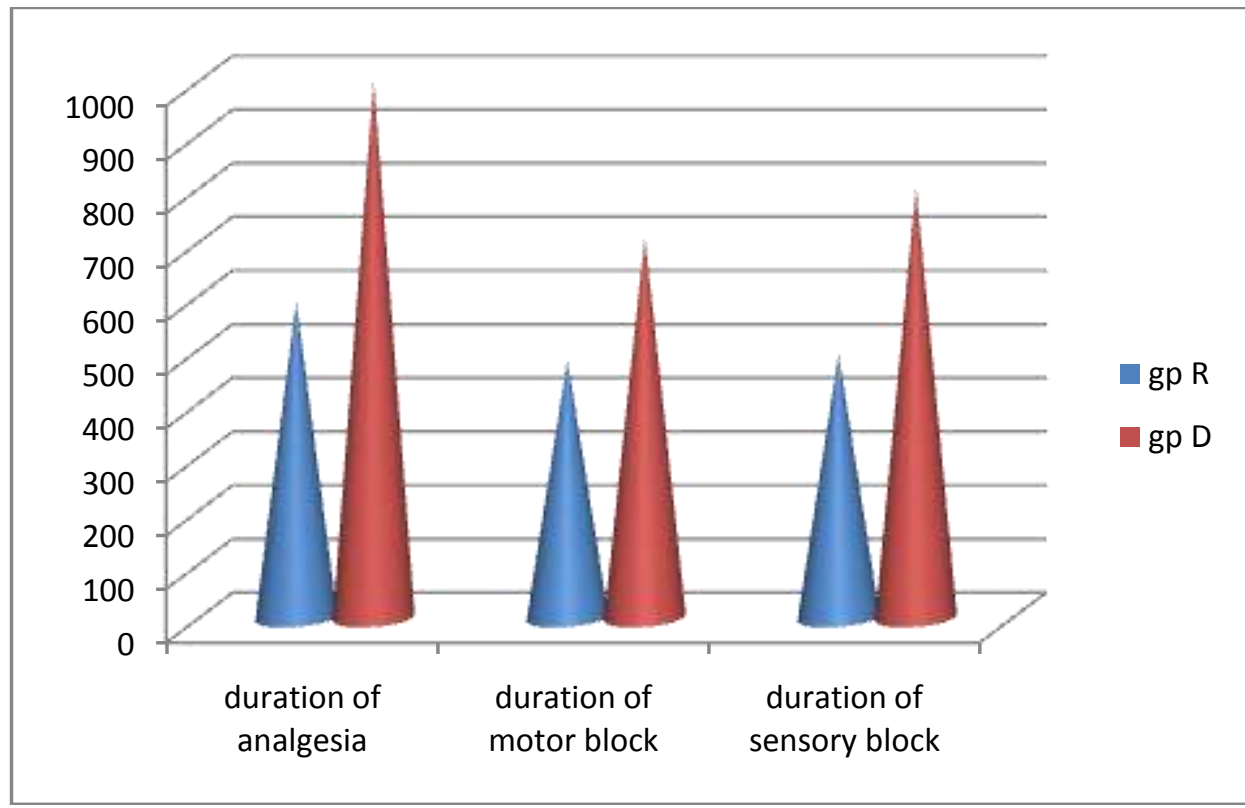

Table 4: Degree of sedation [according to Ramsay Sedation Score(RSS)]

\begin{tabular}{|l|l|l|l|}
\hline & Degree of sedation & gp R & gp D \\
\hline 1 & Awake and alert (RSS 1,2) & 18 & 6 \\
\hline 2 & $\begin{array}{l}\text { Drowsy but responding to } \\
\text { commands (RSS 3,4) }\end{array}$ & 8 & 22 \\
\hline 3 & $\begin{array}{l}\text { Very drowsy but responding to pain } \\
\text { (RSS 5) }\end{array}$ & 4 & 2 \\
\hline 4 & Unresponsive (RSS 6) & 0 & 0 \\
\hline
\end{tabular}

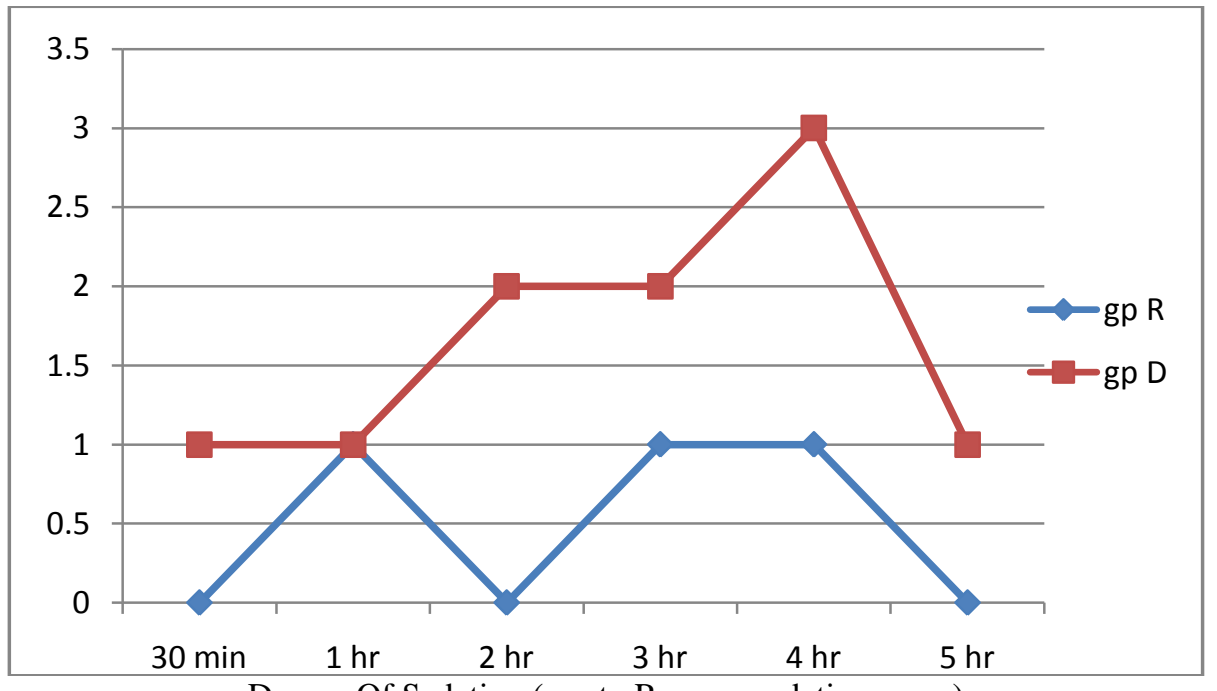

Degree Of Sedation (acc to Ramsay sedation score)

Table 5:

\begin{tabular}{|l|l|l|l|l|}
\hline & Adverse effect & gp R & gp D & p value \\
\hline 1 & Hypotension & 0 & 1 & .86 \\
\hline 2 & Bradycardia & 1 & 2 & .67 \\
\hline 3 & Nausea/vomiting & 2 & 1 & .92 \\
\hline 4 & Headache & 0 & 0 & .9 \\
\hline 5 & Dryness of mouth & 1 & 2 & .67 \\
\hline & Block related & & & .9 \\
6 & Pneumothorax & 0 & 0 & .9 \\
7 & Horner's syndrome & 0 & 0 & \\
\hline
\end{tabular}


No episode of hypoxemia or respiratory depression during $24 \mathrm{~h}$ period postoperatively was seen in any patient. Patients in group D were more sedated compared to group R especially the RSS score was higher in gp $\mathrm{D}$ in first 4 to 6 hours thereafter difference was not statistically significant. Most of the patients in our study had sedation grade $\leq 3$. None of the patient had episodes of hypoxia. Bradycardia was observed in 10 patients in gp $\mathrm{D}$ (mostly within 3 hours after block) which was significant as compared to gp $\mathrm{R}$ where only 1 patient had bradycardia. But HR was never $<55$ in any of the patients of either group and this was managed efficiently by injection atropine sulfate $0.6 \mathrm{mg}$ IV. Hypotension was observed in 4 patients in gp D, which was effectively treated with incremental $3 \mathrm{mg}$ IV boluses of injection mephentermine or I/V fluid boluses. Again the BP was never below 80 systolic in either of the groups. Skin rash was observed in one patient belonging to group D that was treated with injection pheniramine maleate $45.5 \mathrm{mg}$ IV. None of our patients had pneumothorax or horner's syndrome. There were no drop outs in our study and no incidence of a failed block.

\section{Discussion}

Sessler et al., demonstrated that regional anaesthesia to upper extremity is a suitable alternative to general anaesthesia and confers significant benefit to patient improving safety. ${ }^{25,26}$ It minimises the stress response, and avoids opioid-related complications.

Supraclavicular blocks are performed at the level of the brachial plexus trunks. Here, almost the entire sensory, motor and sympathetic innervations of the upper extremity are carried in just three nerve structures (trunks), confined to a very small surface area. Consequently, typical features of this block include rapid onset, predictable and dense anesthesia along with its high success rate. ${ }^{27}$ But the limiting factor in the more widespread use of this block is the duration of action of the local anaesthetics available which means either use of perineural catheters for longer surgeries or addition of adjuvants which prolong the duration of motor and sensory block and analgesia.

Dexmedetomidine, a highly selective, $\alpha_{2}$-adrenergic agonist; has analgesic, sedative, anesthetic sparing effects when used in systemic route. ${ }^{28}$ Use of dexmedetomidine as an adjuvant mixed with local anesthetics has been performed with neuraxial anesthesia in both adult and pediatric patients. ${ }^{29,30}$

We used $0.5 \%$ ropivacaine for supraclavicular block. The rationale for choosing this concentration is supported by the study done by Klein et al. in 1998, who found that for interscalene brachial plexus block, increasing the concentration of ropivacaine from $0.5 \%$ to $0.75 \%$ failed to improve onset or duration of block, suggesting that the risk of increased total dose of local anesthetic may be avoided. ${ }^{31}$ Hickey and coworkers have shown that $0.25 \%$ ropivacaine when used for subclavian perivascular brachial plexus block for upper limb surgery required frequent analgesia supplementation due to the low concentration of local anesthetic used. ${ }^{32}$

Studies comparing acute toxicity of ropivacaine to bupivacaine found that ropivacaine was at least $25 \%$ less toxic than bupivacaine with regard to tolerated doses with the threshold for CNS toxicity for ropivacaine being twice that of bupivacaine. ${ }^{33}$ Geiger and colleagues reported safe use of $1 \%$ ropivacaine up to $500 \mathrm{mg}$. In this study, upto $150 \mathrm{mg}(0.5 \%)$ of ropivacaine was found to produce satisfactory sensory and motor blockade with stable hemodynamic profile and no sign of neuro and cardio toxicity. ${ }^{34} \mathrm{We}$ did not determine plasma concentration of ropivacaine in our patients but studies of systemic disposition of ropivacaine after brachial plexus injection have demonstrated that plasma concentration increases slowly and up to $250 \mathrm{mg}$ have been injected in peripheral nerve block without concern. ${ }^{35}$

The demographic profile, between two groups, which was statistically insignificant $(P>0.05)$ of our patients was quite similar with other research investigations and provided us the uniform platform to evenly compare the results obtained. A study on the role of dexmedetomidine for post-operative analgesia was conducted by Gupta et al in a total of 100 patients yielded similar results. ${ }^{36}$ The mean duration of surgery and tourniquet time were almost comparable in both groups with no significant statistical difference [Table 1].

From Table 2, it is quite evident that indications of surgical procedures were almost similar in both groups and had no statistical significance. The onset time of sensory block in group D (12.68 \pm 2.24 min) was much earlier than in group R $(21.1 \pm 6.84 \mathrm{~min})$. Ammar and Mahmoud and Kaygusuz et al. in their studies also found significantly earlier onset of sensory block in the RD group than in the group R. ${ }^{37,38}$ Anjan et al and Rancourt et al in their study, however, found no difference in the onset of either sensory block or motor block in ropivacaine group and dexmedetomidine group. The onset time of motor block was also much earlier in gp D than in gp R. Ammar and Mahmoud, Gandhi et al in their study also found that motor block onset was hastened by the use of dexmedetomidine adjuvant in brachial plexus block with bupivacaine. Again in a study conducted by Marhofer et al in 36 volunteers it has been found that dexmedetomidine as adjuvant though produced early onset of motor block, sensory block was not different from the control group or i.v group. ${ }^{39}$

Harshvardhan HS in his study comparing the effects of adding Clonidine and Dexmeditomidine to $0.75 \%$ Ropivacaine for supraclavicular nerve blocks also found a significantally faster onset time and duration of sensory and motor block with the addition of dexmeditomidine, which is same as our study. ${ }^{40}$ In our study, the duration of sensory block $(802.04 \pm 154.66 \mathrm{~min}$ in gp D as compared to $492.54 \pm 78.14$ in gp D) was 
significantly longer in the dexmedetomidine group than in the control group $(P<0.001)$. The duration of motor block (710.138 $\pm 12 \mathrm{~min}$ in gp D as compared to $478.12 \pm 122.68 \mathrm{~min}$ in gp R) was also significantly longer in the dexmedetomidine group than in the control group $(P<0.001)$. These findings lend support to the observations of various earlier studies by Ammar and Mahmoud, Esmaoglu et al, Rancourt et al, Swamy SS et al, Marhofer et al and Anjan das et al. ${ }^{17,20,37,39,43}$

Again the median duration of sensory and motor block in the dexmedetomidine plus levobupivacaine group in infraclavicular brachial plexus block were $14.78 \mathrm{~h}$ and $12.88 \mathrm{~h}$ respectively, in the study by Esmaoglu et al. A longer duration of motor block may be advantageous for orthopaedic patients in whom early ambulation may not be desired.

In 2012, Gandhi $\mathrm{R}$ et al conducted a study to compare the postoperative analgesic efficacy and safety of dexmedetomidine for brachial plexus blockade along with bupivacaine. They observed that dexmedetomidine group had prolonged postoperative analgesia. ${ }^{44}$ In our study, patients of RD group required significantly less number of diclofenac sodium injection in first $24 \mathrm{~h}$ of post-operative period than the patients $\mathrm{R}$ group $(P<$ 0.01). This finding correlates with the studies of Kaygusuz et al. Kaygusuz et al found that 11 patients of levobupivacaine group required $75 \mathrm{mg}$ intramuscular injection of diclofenac sodium as rescue analgesic, whereas dexmedetomidine plus levobupivacaine group required nothing and the result was also statistically significant. Reduced requirement of rescue analgesic in the dexmedetomidine group during first $24 \mathrm{~h}$ of postoperative period is because of prolonged duration of sensory block.

In our study the drop in heart was observed more in dexmedetomidine group than ropivacaine group but it was managed with I/V atropine. Esmaoglu et al. also found significant bradycardia in dexmedetomidine plus levobupivacaine group than levobupivacaine alone.

The mechanism of this analgesic action is not very clear. Probabaly peripherally $\alpha 2$ agonists produce analgesia by reducing the release of norepinephrine and also causing inhibitory effects on the nerve fibre action potentials which is receptor independent. Central analgesia and sedation by these drugs is caused by the inhibition of release of substance $\mathrm{P}$ in the nociceptive pathway at the level of the dorsal root neurons and by activating the $\alpha 2$ receptors in the locus cerulus. The locus ceruleus is also the site of origin for the descending medullospinal noradrenergic pathway, known to be an important modulator of nociceptive neurotransmission. Dexmedetomidine and clonidine are both $\alpha 2$ adrenergic agonists. However the novel $\alpha 2$ agonist dexmedetomidine has eight times higher selectivity to $\alpha 2$ adrenoceptors. ${ }^{41,42}$

In this study, large volume and higher concentration of ropivacaine was used and in addition, close deposition of drug in the vicinity of nerve plexus using nerve locator may be the major factors in increasing the rate of satisfactory block. It is striking to note that except one patient in ropivacaine group, none of the patient in either group required supplementation.

In this study, identification of brachial plexus was done with the help of nerve locater. This technique was specifically chosen as evaluation of any drug for neural blockade needs close deposition of drug in the vicinity of nerve plexus. We specially selected forearm orthopedic surgery as contraction of muscles due to nerve stimulation is unwanted in arm fractures. Another technique for administration of local anesthetic in close proximity of nerve plexus is ultrasonography guided block, which is more acceptable and useful but needs availability of sonography and experience in the technique.

Another limitation of our study was that only ASA grade I and II were included in the study for supraclavicular block. The effect of dexmedetomidine also needs to be evaluated in compromised patients (ASA grade III and IV) in whom general anaesthesia may not be possible or associated with high risk.

\section{Conclusion}

We conclude that addition of dexmedetomidine $(100 \mu \mathrm{g})$ to $29 \mathrm{ml}$ ropivacaine $0.5 \%$ in supraclavicular brachial plexus block using nerve stimulator resulted in a quick onset of sensory and motor block, prolonged duration of both sensory and motor block delayed time to first request for analgesia supplementation, that is, prolonged duration of analgesia, and significantly decreased $24 \mathrm{~h}$ analgesic consumption and a good quality of analgesia when compared with control group (ropivacaine $0.5 \%$ alone in block).

\section{Bibliography}

[1]. Sng, B. L., \& Schug, S. A. The role of opioids in managing chronic non-cancer pain. Ann Acad Med Singapore,2009. 38(11), 9606.

[2]. Suchdev PK. Pathophysiology of Pain. In: Warfield CA, Fausett HJ. Manual of Pain Management: 2nd edition. Philadelphia: Lippincott Williams and Wilkins; 2002. 6-12.

[3]. Kulenkampff D, Persy MA. Brachial plexus anesthesia: its indications, technique and dangers. Ann Surg 1928; 87:883-91.

[4]. Lanz E, Theiss D, Jankovic D. The extent of blockade following various techniques of brachial plexus block. AnesthAnalg $1983 ; 62: 55-8$

[5]. Halstead C. Great moments in the history of anaesthesiology. In: A Practice of Anesthesia. 7th ed. London, UK: LioydLuke;2003.5. 
[6]. Scott DB, Lee A, Fagan D, Bowler GM, Bloomfield P, Lundh R. Acute toxicity of ropivacaine compared with that of bupivacaine. Anesth Analg. 1989;69:563-69.

[7]. Arthur GR, Feldman HS, Covino BG. Comparative pharmacokinetics of bupivacaine and ropivacaine, a new amide local anesthetic. Anesth Analg. 1988;67:1053-58.

[8]. Bazin JE, Massoni C, Bruelle P, Fenies V, Groslier D, Schoeffler P. The addition of opioids to local anaesthetics in brachial plexus block: the comparative effects of morphine, buprenorphine, and sufentanil. Anaesthesia 1997; 52: 858-62.

[9]. Culebras X, Van Gessel E, Hoffmeyer P, Gamulin Z. Clonidine combined with a long acting local anaesthetic does not prolong postoperative analgesia after brachial plexus block but does induce hemodynamic changes. Anaesth Analg 2001; 92: 199-204

[10]. Bone HG, Van Aken H, Brooke M, Burkle H.Enhancement of axillary brachial plexus block anaesthesia by co-administration of neostigmine.Regional Anaesthesia Pain Med 1999;24:405-10.

[11]. Keeler JF, Simpson KH, Ellis FR, Kay SP. Effect of addition of hyaluronidase to bupivacaine during axillary brachial plexus block. Br J Anaesth 1992; 68: 68-71.

[12]. Shrestha BR, Maharjan SK, Tabedar S, supraclavicular brachial plexus block with and without dexamethasone- A comparative study. Kathmandu University Medical Journal $2003 ; 1 ; 3$ : 158-60.

[13]. Popping DM, Elia N, Marret E, Wenk M, Tramèr MR. Clonidine as an adjuvant to local anaesthetic for peripheral nerve and plexus blocks: A meta-analysis of randomized trials. Anesthesiology 2009;111:406-15.

[14]. Raimo V, Juha M, Veijo S, Leena N, Virtanen R. Characterisation of selectivity, specificity and potency of dexmedetomidine as $\alpha 2$ adrenoceptor agonist. Eur J Pharmacol 1988;150:9-14.

[15]. Chakraborty, Susmita, et al. "Effect of clonidine as adjuvant in bupivacaine-induced supraclavicular brachial plexus block: A randomized controlled trial."Indian journ of pharmacol,2010; 42.2:74.

[16]. Keniya VM, Ladi S, Naphade R. Dexmedetomidine attenuates sympathoadrenal response to tracheal intubation and reduces perioperative anaesthetic requirement. Indian J Anaesth 2011;55:352-7.

[17]. Esmaoglu A, Yegenoglu F, Akin A, Turk CY. Dexmedetomidine added to levobupivacaine prolongs axillary brachial plexus block. Anaesth Analg 2010;111(6):1548-51.

[18]. Obayah GM, Refaie A, Aboushanab O, Ibraheem N, Abdelazees M. Addition of dexmedetomidine to Bupivacaine for greater palatine nerve block prolongs postoperative analgesia after cleft palate repair. Eur J Anaesthesiol 2010;27:280-4.

[19]. Jiljil Kavitha, Bhatnagar Vidhu, P Swapna, Urvashi Tondon. Comparative evaluation of Alpha two agonists Dexmedetomidine with Clonidine as adjuvants to $0.25 \%$ Ropivacaine for Ultrasound Guided Supraclavicular Block: A randomised double-blind prospective study. International J. of Healthcare and Biomedical Research 2015; 3:20-31.

[20]. Das A, Majumdar S, Halder S, Chattopadhyay S, Pal S, Kundu R, Mandal SK, Chattopadhyay S. Effect of dexmedetomidine as adjuvant in ropivacaine-induced supraclavicular brachial plexus block: A prospective, double-blinded and randomized controlled study. Saudi J Anaesth 2014;8, Suppl S1:72-7.

[21]. Ramsay MA, Savage TM, Simpson BR, Godwin R. Controlled sedation with alphaxolone-alphadolone. Br Med J 1974;2:656-9.

[22]. Singh R, Gupta D, Jain A. The effect of addition of intrathecal clonidine to hyperbaric bupivacaine on postoperative pain after lower segment caesarean section: A randomized control trial. Saudi J Anaesth. 2013 Jul-Sep; 7(3): 283-90.

[23]. Bromage PR. Philadelphia: WB Saunders; 1978:144.

[24]. Memis D, Turan A, Karamanlioglu B, Pamukçu Z, Kurt I. Adding dexmedetomidine to lignocaine for IVRA. Anesth Analg 2004;98:835-40.

[25]. Sessler DI, Rubinstein EH, Moayeri A. Physiological responses to mild perianesthetic hypothermia in humans. Anesthesiology 1991;75:594-610.

[26]. Sessler DI. Perioperative hypothermia. New England Journal of Medicine 1997;336:1730-77.

[27]. Singh S, Aggarwal A. A randomized controlled double-blinded prospective study of the efficacy of clonidine added to bupivacaine as compared with bupivacaine alone used in supraclavicular brachial plexus block for upper limb surgeries. Indian $\mathbf{J}$ Anaesth. 2010;54:552-7.

[28]. Huang R, Hertz L. Receptor subtype and dose dependence of dexmedetomidine-induced accumulation of [14C] glutamine in astrocytes suggests glial involvement in its hypnotic-sedative and anesthetic-sparing effects. Brain Res. 2000;873:297-301.

[29]. Al-Ghanem SM, Massad IM, Al-Mustafa MM, Al-Zaben KR, Qudaisat IY, Qatawneh AM, et al. Effect of adding dexmedetomidine versus fentanyl to intrathecal bupivacaine on spinal block characteristics in gynaecological procedures: A double blind controlled study. Am J Appl Sci. 2009;6:882-7.

[30]. El-Hennawy AM, Abd-Elwahab AM, Abd-Elmaksoud AM, El-Ozairy HS, Boulis SR. Addition of clonidine or dexmedetomidine to bupivacaine prolongs caudal analgesia in children. Br J Anaesth. 2009;103:268-74.

[31]. Klein SM, Greengrass RA, Steele SM, D'Ercole FJ, Speer KP, Gleason DH, et al. A comparison of $0.5 \%$ bupivacaine, 0.5\% ropivacaine, and 0.75\% ropivacaine for interscalene brachial plexus block. Anesth Analg 1998;87:1316-9.

[32]. Hickey R, Rowley CL, Candido KD, Hoffman J, Ramamurthy S, Winnie AP. A comparative study of $0.25 \%$ ropivacaine and $0.25 \%$ bupivacaine for brachial plexus block. Anesth Analg 1992;75:602-6.

[33]. Knudsen K, Beckman Sukula M, Blomerg S. Central nervous and cardiovascular effect of IV infusion of ropivacaine, bupivacaine and placebo in volunteers. Br J Anaesth 1997; 78: 507-14.

[34]. Geiger P, Oldenburger K, Ventour W, Mehrkens HH. Ropivacaine $0.5 \%$ vs $0.75 \%$ vs $1 \%$ for 3 -in- 1 block combined with sciatic nerve block in orthopaedic surgery.7th Annual ESRA Congress, Geneva.1998;47.

[35]. Tripathi D, Shah K, Shah C, Shah S, Das E. Supraclavicalar Brachial Plexus Block for Upper Limb Orthopedic Surgery: A Randomized, Double Blinded Comparison Between Ropivacaine And Bupivacaine. The Internet Journal of Anesthesiology.2012;30:4.

[36]. Gupta R, Bogra J, Verma R, Kohli M, Kushwaha JK, Kumar S. Dexmedetomidine as an intrathecal adjuvant for postoperative analgesia. Indian J Anaesth. 2011;55:347-51.

[37]. Ammar AS, Mahmoud KM. Ultrasound-guided single injection infraclavicular brachial plexus block using bupivacaine alone or combined with dexmedetomidine for pain control in upper limb surgery: A prospective randomized controlled trial. Saudi $\mathbf{J}$ Anaesth. 2012;6:109-14.

[38]. Kaygusuz K, Ozdemir I, Duger C, Gursoy S, Ozturk H, Kayacan U, et al. Effects of adding dexmedetomidine to levobupivacaine in axillary brachial plexus block. Curr Ther Res. 2012;73:103-11.

[39]. Marhofer D, Kettner SC, Marhofer P, Pils S, Weber M, Zeitlinger M. Dexmedetomidine as an adjuvant to ropivacaine prolongs peripheral nerve block: A volunteer study. Br J Anaesth. 2013;110:438-42.

[40]. Harshvardhan HS. Efficacy of Dexmedetomidine Compared to Clonidine added to Ropivacaine in Supraclavicular Nerve Blocks: A Prospective, Randomized, Double Blind Study.Int J Med Health Sci.2014; 3(2):127-32. 
[41]. Kosugi T, Mizuta K, Fujita T, Nakashima M, Kumamoto E. High concentrations of dexmedetomidine inhibit compound action potentials in frog sciatic nerves without alpha(2) adrenoceptor activation. Br J Pharmacol. 2010;160:1662-76.

[42]. Fürst S. Transmitters involved in antinociception in the spinal cord. Brain Res Bull. 1999;48:129-41.

[43]. Swami SS, Keniya VM, Ladi SD, Rao R. Comparison of dexmedetomidine and clonidine (alpha 2 agonist) as an adjuvant to local anaesthesia in supraclavicular brachial plexus block: A randomised double-blind prospective study. Indian J Anaesth. 2012;56:2439.

[44]. Gandhi R, Shah A, Patel I. Use of dexmedetomidine along with bupivacaine for brachial plexus block. Natl J Med Res. 2012; 2(1):67-69. 